\title{
Contact lens fitting after photorefractive keratectomy
}

\author{
C L K Astin, D S Gartry, A D McG Steele
}

\begin{abstract}
Aims/background-This study evaluated contact lens fitting and the longer term response of the photorefractive keratectomy (PRK) cornea to lens wear. In PRK for myopia problems such as regression, anterior stromal haze, irregular astigmatism, halo aberration, and anisometropia have been reported. Certain patients therefore require contact lens correction to obtain best corrected visual acuity (BCVA).

Method-From an original cohort of 80 patients, 15 were dissatisfied with their visual outcome 6 months after PRK. Ten of these were fitted with lenses and monitored regularly.

Results-The best fit rigid gas permeable lens of diameter $9.20-10.00 \mathrm{~mm}$ was generally $0.10 \mathrm{~mm}$ steeper than mean keratometry readings. Because of lid discomfort five patients were refitted with daily wear soft lenses. All 10 achieved satisfactory lens wear of 10 hours per day. Central corneal steepening of $0.75 \mathrm{D}(0.15$ $\mathrm{mm}$ ) occurred in one patient. Two patients had slight central corneal flattening. Three patients discontinued lens wear as they found lens care a nuisance. Four finally opted for retreatment by PRK.

Conclusions-In most cases, contact lenses gave good visual acuity and, in cases of mild irregular astigmatism, a significant improvement over spectacle BCVA. No significant adverse reaction to contact lens wear was found. Although ocular tolerance of lenses was satisfactory, several patients discontinued lens wear or sought improved unaided vision.

(Br F Ophthalmol 1996;80:597-603)
\end{abstract}

Phototherapeutic keratectomy (PTK) and photorefractive keratectomy (PRK) using the argon fluoride excimer laser with emission wavelength of $193 \mathrm{~nm}$ have been the subjects of clinical investigation for over 6 years. ${ }^{1-27}$ Two features of excimer laser radiation at this wavelength make it eminently suitable for corneal surgery. Firstly, the photon energy at $193 \mathrm{~nm}$ is high (around $6 \mathrm{eV}$ ) and exceeds the binding voltages of molecules within the cornea. On exposure to this wavelength molecular bonds within the corneal surface are broken and the constituent fragments are ejected from the surface at high speed. With optimal particle fluence (around $200 \mathrm{~mJ} / \mathrm{cm}^{2}$ ) and repetition rate $(5-10 \mathrm{~Hz})$ there is minimal thermal damage to nearby tissues. ${ }^{28}$ Corneal tissue can be removed with an unprecedented submicrometre precision leaving a relatively smooth surface. Secondly, the cross sectional area of the beam is large and can be configured in a variety of shapes. When combined with a computer controlled iris diaphragm the corneal surface can be reprofiled directly to effect a refractive change. The term 'photorefractive keratectomy' or PRK was first introduced by Marshall et al in $1988^{29}$ and over the past 2 to 3 years PRK for the treatment of myopia has become widely available. Tens of thousands of patients have undergone the procedure.

Information regarding the corneal wound healing response after PRK has become available following research at several centres in Europe and the USA. ${ }^{1-27}$ It has been found that after PRK there is deposition of new material (glycosaminoglycans, mucopolysaccharides, new disorganised collagen) beneath the epithelium and this, in addition to epithelial hyperplasia, is responsible for the common trend towards regression or loss of the refractive change. In addition, varying degrees of subepithelial or anterior stromal haze have been documented in the majority of patients and these changes along with irregular astigmatism account for the loss of best corrected visual acuity (BCVA) in around 10-15\% of patients. $^{8}{ }^{13}{ }_{23}{ }_{25}$ Moreover, the rehabilitation phase following PRK is prolonged. An initial overcorrection to the hypermetropic state is followed by regression to a stable, and often undercorrected (myopic) endpoint over a period of several months. ${ }^{6-27}$ Because of significant regression, and as PRK becomes more widely available, there will be an increasing number of patients requiring correction with contact lenses after PRK. Other indications for contact lens fitting after PRK are induced anisometropia and irregular astigmatism. It has been shown that a small but significant number of patients who were highly myopic originally may, because of the deeper ablation, have residual irregular astigmatism after PRK and therefore may need rigid contact lenses in order to achieve their best visual acuity. ${ }^{8}$ Also, patients who have been overcorrected (rendered hypermetropic) by PRK may request contact lenses. This will be especially true of presbyopes. In view of these considerations a knowledge of the corneal and visual changes that occur after PRK and the requirements for satisfactory contact lens wear are important when fitting contact lenses following this procedure.

It was hypothesised that potential problems of contact lens wear following PRK might include poor centration and excessive move- 
ment of the lens, the formation of a central tear pool (resulting in a positive 'tear lens') beneath the contact lens, and poor longer term tolerance of the PRK cornea to contact lens wear. This study was designed therefore to evaluate the technical fitting difficulties and the response of the PRK cornea to contact lens wear.

\section{Materials and methods}

Following ethics committee approval a research programme to investigate PRK commenced in December 1990 at Moorfields Eye Hospital. An early Excimed UV200 excimer laser (Summit Technology, Waltham, MA, USA) was used with ablation zone diameters varying between 4 and $5 \mathrm{~mm}$. Preliminary results have been reported elsewhere. ${ }^{11}$ Of the original cohort of 80 patients (myopia range -1.50 to -7.00 D) $15(19 \%)$ were dissatisfied with their visual outcome at the 6 month stage. Ten of these patients were enrolled into this study and were fitted with contact lenses to correct residual myopia or irregular astigmatism. The remaining five were similar in refraction to the fitted patients. Their 12 month post-PRK refraction range was from -0.50 to $-5.50 \mathrm{D}$. There was some degree of haze in the ablation zone, similar to that in the fitted group. Their personal choice was to decline lens fitting because of the nuisance of lens care. This had been their main reason for seeking PRK treatment. In four of the 10 cases refraction was stable at 6 months after PRK and contact lenses were fitted. Six patients were fitted following the 12 month visit to ensure cor- neal topographic and refractive status stabilisation. The post-PRK refraction range at the 6 month stage was -1.00 to $-6.00 \mathrm{D}$ (mean $-2.45 \mathrm{D}$ ). Mean age was 35 (range 24-44) years and the male:female ratio was 6:4. Five patients (Nos 2, 7, 8, 9, 10; Table 1) had a low degree of induced irregular astigmatism as shown by keratometer mire distortion and videokeratoscopy (Fig 1). Mean follow up was 18 months (range 6 months to 2 years).

Monitoring comprised refraction, keratometry (Topcon 1), videokeratoscopy (EyeSys), and pachymetry (Haag-Streit with fixation attachment). Patients attended for follow up at 2 weeks, 6 weeks, and 3,6,12, 18, and 24 months.

\section{Results}

\section{LENS FITTING DETAIIS}

All 10 patients were fitted initially with rigid gas permeable (RGP) contact lenses which were found to 'bridge' the central ablated zone easily. Lens support therefore was provided primarily by the corneal periphery (Fig 2). The best fit was usually achieved when using a lens of back optic zone radius (BOZR) $0.25 \mathrm{~mm}$ $(1.25 \mathrm{D})$ steeper than the flattest keratometer reading. This was, on average $0.10 \mathrm{~mm}(0.50$ D) steeper than the mean keratometry readings. The overall diameter of the RGP lenses used was 9.20 to $10.00 \mathrm{~mm}$, depending on individual requirement and lens design. Lens fit was assessed with fluorescein and a Burton lamp. The aim was a lens which centred well, had adequate movement to allow good tear exchange, and gave stable visual acuity. In

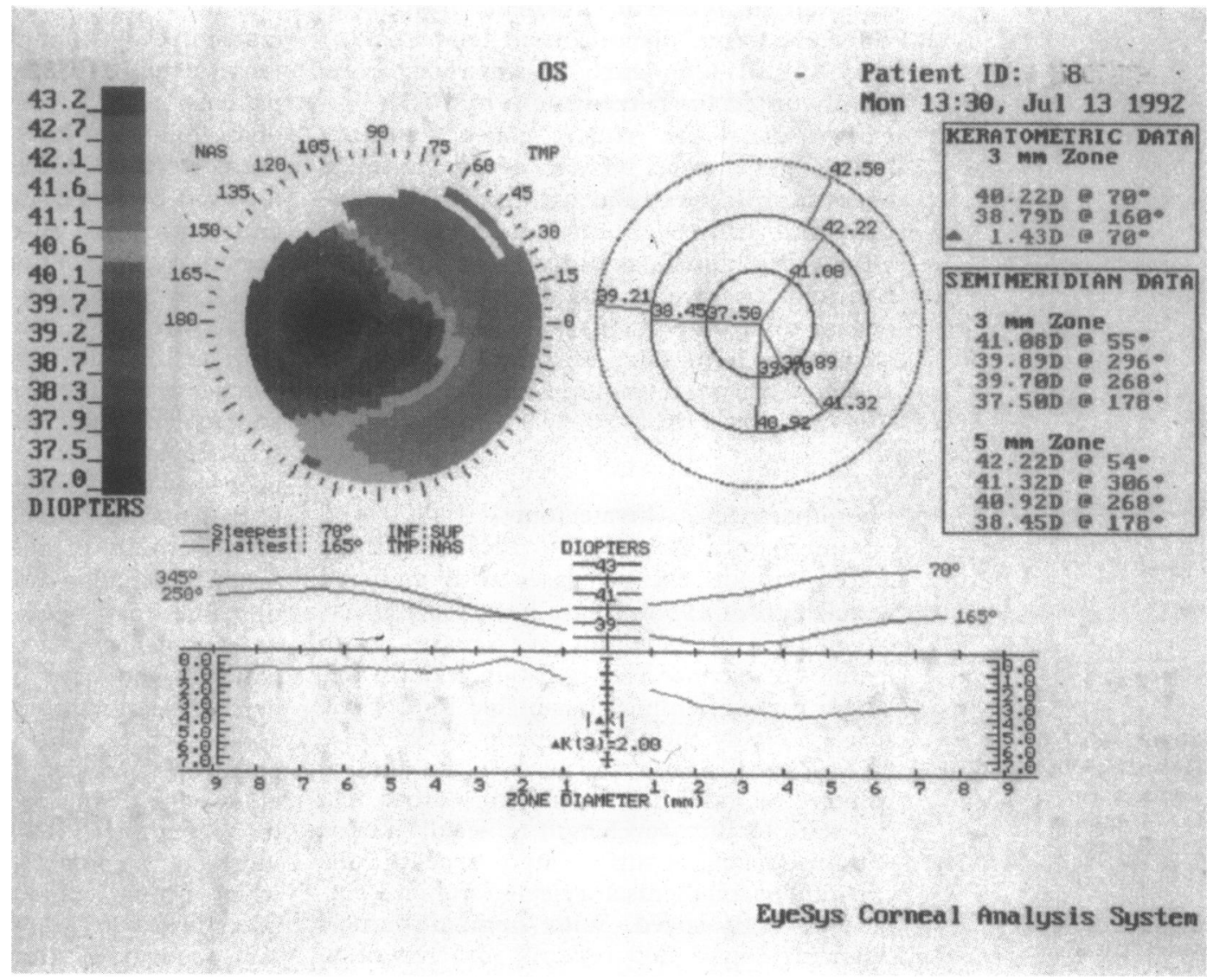

Figure 1 Irregular astigmatism shown by videokeratoscopy. The decentred flattened zone is shaded dark grey and is nasal to the ideal position. 
addition, the lens material was selected for good 'wettability' to minimise risk of adherence to the regenerated central epithelium. Lenses with an aspheric back surface were selected with the intention that the peripheral bearing zones would approximate the peripheral corneal contours more closely providing a more even distribution of lens pressure, smooth lens movement, and good tear exchange.

As a result of lid discomfort five patients were refitted with daily wear soft lenses. The same five patients $(3,6,7,9,10$; Table 1$)$ had experienced similar lid problems when wearing RGP lenses before undergoing PRK. A 14.00 $\mathrm{mm}$ diameter soft lens was chosen of medium to high water content for good oxygen

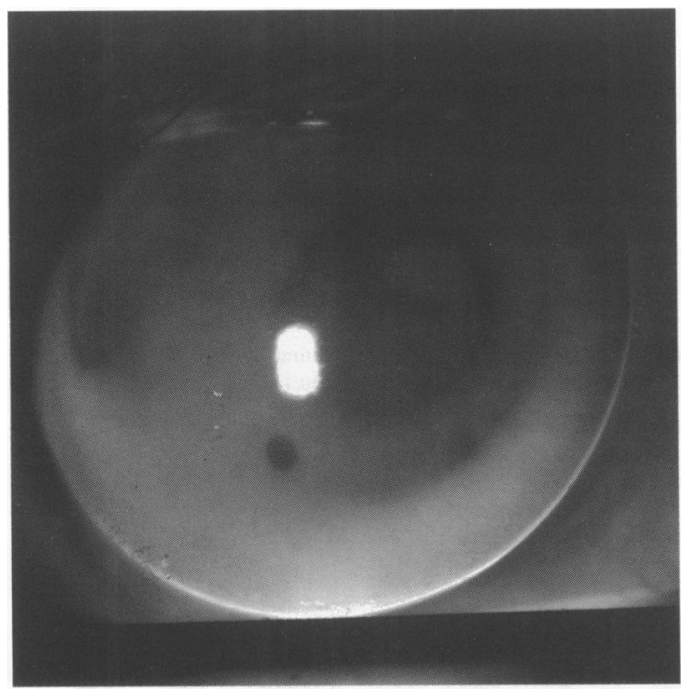

Figure 2 Good tear exchange beneath rigid lens. Inferiorly, the area of maximum tear exchange beneath the lens is indicated by the light shading, which represents the green fluorescence of fluorescein. The mid peripheral bearing areas are seen more easily above and either side of the central tear pool.

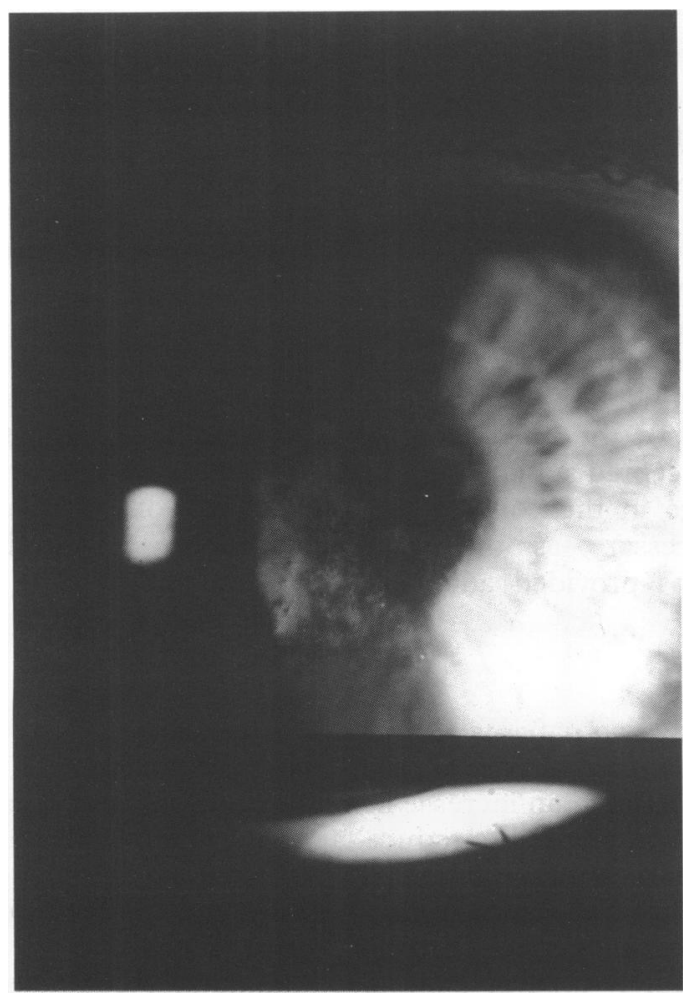

Figure 3 Reticulate anterior corneal stromal haze. transmissibility and the 'first choice' lens had a BOZR radius of curvature $0.30 \mathrm{~mm}(1.50 \mathrm{D})$ flatter than the flattest keratometry value. The soft lens fit was assessed by good lens centration, adequate movement of 0.5 to 1.0 mm on blinking, and the lack of conjunctival or limbal vessel indentation or 'blanching' after the 20 minutes allowed for settling.

The RGP lenses used were Persecon Elliptical $E$ and 92E (CibaVision), Novalens, and Metro-GP (CLM Ltd). The soft lenses used were CSI (Pilkington), thin Hema (Hydron), and Optima 60 (Moorfields). Power ranged from -0.50 to $-4.00 \mathrm{D}$, the RGP lenses having up to $0.50 \mathrm{D}$ extra power to cancel out the positive power of the tear pool (tear lens). As for any contact lens, adequate oxygen transmissibility of the lens material is desirable to reduce the risk of corneal hypoxia. Before fitting, no clinical evidence of corneal hypoxia had been noted in the PRK eyes when compared with the untreated eyes. However, each case was monitored and lens wear adjusted to suit individual requirements. For example, in cases 6 and 7 the visual acuity with the RGP lens was reasonable but tolerance was limited by lid sensation. Refitting with daily wear soft lenses was successful and wearing time increased to 12-14 hours a day.

\section{OUTCOME}

The preoperative details, contact lens specifications, and outcome for each patient are summarised in Table 1 . All 10 patients were able to wear the final choice of lens comfortably for 10 to 14 hours a day. No clinical signs of corneal oedema were detected throughout the follow up period. A best contact lens corrected visual acuity (BCLCVA) of $6 / 6(20 / 20)$ was obtained in eight eyes although two of these patients ( 1 and 5) experienced visual 'blur', equivalent to a loss of 1 line of Snellen on average, due to lens greasing after 9 hours of wear. The remaining two patients (7 and 9) achieved a BCLCVA of $6 / 9+(20 / 30)$, in comparison with their prePRK BCVA of $6 / 6$ for patient 7 and $6 / 5$ for patient 9, the result of reticulate anterior corneal stromal haze and/or irregular astigmatism (Fig 3).

\section{Keratometry and keratoscopy}

Figure 1 is a videokeratoscopic topographical map 12 months after PRK. The central dark region indicates the flatter curvature of the ablated zone over which the contact lens vaults. The $4.0 \mathrm{~mm}$ diameter pupil was within the position of the $4.5 \mathrm{~mm}$ diameter ablation zone. Six patients $(2,4,7,8,9$, and 10 ; Table 1$)$ had slight induced irregular astigmatism detected by mire distortion which was not present before PRK. A RGP contact lens successfully masked this irregularity. Few adverse post lens wear changes were demonstrated. Slight flattening of the central cornea (by $0.10 \mathrm{~mm}(0.50$ D) for patient 9 and $0.06 \mathrm{~mm}(0.25 \mathrm{D})$ for patient 3) and further reduction of myopia were noted in two patients after 8 to 10 hours of soft lens wear. Patient 5, fitted with a RGP lens, showed central corneal curvature steepening by $0.15 \mathrm{~mm}(0.75 \mathrm{D})$. This was not 
Table 1 Refraction and keratometry after photorefractive keratectomy (PRK) and contact lens (CL) outcome in 10 patients

\begin{tabular}{|c|c|c|c|c|c|c|c|}
\hline Patient No & Pre-PRK details & 1 week post-PRK & 12 months post-PRK & Pre-CL fitting & $C L$ in situ & Post $C L$ wear & Final outcome \\
\hline (1) & & Irregular & Regular & 6 months post op & Metro GP & & CL a nuisance gave up \\
\hline Keratometry & 8.08 at $180 / 7.81$ at 90 & 8.90 at $5 / 8.50$ at 95 & 8.38 at $180 / 8.08$ at 90 & 8.50 at $180 / 8.15$ at 90 & $8.10 / 9.60 /(-4.00)$ & 8.32 at $5 / 7.98$ at 95 & after 3 months. Fellow \\
\hline Refraction & $-5.00 /-0.75$ (axis 175 ) & $+1.50 /-2.00($ axis 5$)$ & $-3.00 /-0.75$ (axis 165) & $-2.25 /-1.00$ (axis 170$)$ & Good fit $12 \mathrm{~h}$ wear & $-3.25 /-0.75$ (axis 165$)$ & eye wears a disposable \\
\hline BCVA & $6 / 5-1$ & $6 / 5$ slow & $6 / 5-2$ & $6 / 5$ & $6 / 5$ & $6 / 6$ & \\
\hline (2) & & Regular & Did not attend & 6 months post op & Persecon E & Slightly irregular & Patient gave up $\mathrm{CL}$ as \\
\hline Keratometry & 7.45 at $180 / 7.30$ at 90 & 8.30 at $180 / 8.07$ at 90 & & 7.78 at $180 / 7.60$ at 90 & $7.80 / 9.80 /(-0.75)$ & 7.78 at $180 / 7.60$ at 90 & thinks refraction will \\
\hline Refraction & $-3.00 /-0.50$ (axis 155$)$ & $+2.00 / 0.25($ axis 180$)$ & & $-0.50 /-0.50$ (axis 165) & Good fit $10 \mathrm{~h}$ wear & $-0.50 /-0.50$ (axis 75) & improve in 6 months to \\
\hline BCVA & $6 / 5$ & 6/6 faint haze & & $6 / 5$ hazy & $6 / 5$ & $6 / 5$ hazy & \\
\hline (3) & & Irregular & Slightly irregular & 6 months post op & Optima 60 & & $15-16 \mathrm{~h}$ wear a day. \\
\hline Keratometry & 7.82 at $180 / 7.75$ at 90 & 9.07 at $180 / 8.75$ at 90 & 8.12 at $180 / 8.05$ at 90 & 8.05 at $180 / 7.96$ at 90 & $8.40 / 13.50 /(-3.00)$ & 8.12 at $180 / 8.07$ at 190 & Prefers evening wear as \\
\hline Refraction & $-4.75 \mathrm{sph}$ & $+4.00 \mathrm{sph}$ & $-1.75 /-0.50$ (axis 60) & $-1.75 /-0.50$ (axis 75) & Good fit $15 \mathrm{~h}$ wear & $-1.75 /-0.50($ axis 75$)$ & has a dusty job \\
\hline BCVA & $6 / 5$ & $6 / 9$ hazy & $6 / 5$ hazy & $6 / 5$ & $6 / 6$ & $6 / 5$ & \\
\hline (4) & & Very irregular & Slightly irregular & 12 months post op & Persecon 92E & & Lens good, but patient \\
\hline Keratometry & 7.80 at $180 / 7.54$ at 90 & 9.70 at $180 / 9.80$ at 90 & 8.26 at $175 / 7.83$ at 85 & 8.26 at $175 / 7.84$ at 85 & $8.10 / 9.80 /(-7.00)$ & 8.26 at $175 / 7.84$ at 85 & prefers convenience of \\
\hline Refraction & $-10.00 /-1.50$ (axis 10$)$ & $+9.00 /-2.00$ (axis 15) & $-5.00 /-2.00$ (axis 180) & $-5.00 /-2.00$ (axis 180 ) & $10 \mathrm{~h}$ wear. Amblyopic & $-5.00 /-2.00($ axis 180$)$ & $\begin{array}{l}\text { disposable soft lens } \\
\text { (Acuvue) as for fellow }\end{array}$ \\
\hline BCVA & $6 / 12$ & $6 / 18$ & $6 / 18$ & $6 / 18$ & $6 / 12$ & $6 / 18$ & \\
\hline (5) & & Slightly irregular & & 12 months post op & Persecon 92E & & 12 to $18 \mathrm{~h}$ wear a day. \\
\hline Keratometry & 8.02 at $170 / 7.73$ at 80 & 9.58 at $180 / 9.21$ at 90 & 8.67 at $175 / 8.23$ at 85 & 8.67 at $175 / 8.23$ at 85 & $8.20 / 9.80 /(-4.50)$ & 8.582 at $165 / 8.19$ at 75 & 5 Lateral hyperaemia as \\
\hline Refraction & $-7.00 /-1.25$ (axis 180) & $+6.00 /-1.50($ axis 10$)$ & $-1.25 /-2.00$ (axis177) & $-1.25 /-2.00$ (axis 177) & Good fit $12 \mathrm{~h}$ wear & $-2.50 /-1.50($ axis 170$)$ & poor blinks. Less minus \\
\hline BCVA & $6 / 6$ & $6 / 9$ & $6 / 9$ & $6 / 9$ & $6 / 4$ & $6 / 9$ & not accepted \\
\hline (6) & & Very irregular & Slightly irregular & 12 months post op & LP Nova Quadrant & & $14 \mathrm{~h}$ wear a day with soft \\
\hline Keratometry & 7.08 at $180 / 7.51$ at 90 & 9.25 at $10 / 8.80$ at 100 & 8.09 at $175 / 7.83$ at 85 & 8.09 at $175 / 7.83$ at 85 & $7.90 / 9.20(-3.00)$ & 8.05 at $180 / 7.81$ at 90 & lens, but found lens a \\
\hline Refraction & $-5.25 /-0.50$ (axis 70$)$ & $+5.00 \mathrm{sph}$ & $-1.75 /-0.25$ (axis 180) & $-1.75 /-0.25$ (axis 180) & $\begin{array}{l}\text { re-fitted with Omniflex } \\
\text { soft } 8.40 / 14.30\end{array}$ & -1.50 & $\begin{array}{l}\text { nuisance so } 1.5 \text { year } \\
\text { later had re-treatment }\end{array}$ \\
\hline BCVA & $6 / 5$ & $6 / 9$ & $6 / 6-2$ & $6 / 6-2$ & $(-2.50) 6 / 5$ & $6 / 6$ after $C L$ removed & \\
\hline (7) & & Irregular & Slightly irregular & 9 months post op & Optima 60 soft & Irregular & $12-16 \mathrm{~h}$ wear a day. \\
\hline Keratometry & 7.63 at $87 / 7.91$ at 177 & 9.12 at $165 / 8.67$ at 75 & 7.93 at $80 / 8.28$ at 170 & $\begin{array}{l}8.34 \text { at } 180 \text { irreg/7.84 at } \\
90\end{array}$ & $8.60 / 14.0 /(-2.25)$ & 8.30 at $170 / 8.00$ at 80 & $\begin{array}{l}\text { Disappointed that haze } \\
\text { keeps VA poor }(6 / 9)\end{array}$ \\
\hline Refraction & $-9.00 /-1.75$ (axis165) & plano/- 0.25 (axis 180 ) & $-2.75 /-0.5$ (axis 135) & $-2.00 \mathrm{sph}$ & $12 \mathrm{~h}$ wear & $-2.00 /-1.00($ axis 100$)$ & with ghosting sent for \\
\hline BCVA & $6 / 6-1$ & $6 / 12$ & $6 / 6$ & $6 / 9$ & $6 / 9$ & $6 / 12$ & refit \\
\hline (8) & & & & 12 months post op & RGP Metro GP & Did not attend & $12 \mathrm{~h}$ wear a day. Poor at \\
\hline Keratometry & 7.97 at $180 / 7.75$ at 90 & 9.37 at $180 / 9.24$ at 90 & 8.63 at $180 / 8.48$ at 90 & $\begin{array}{l}8.63 \text { at } 180 \mathrm{irreg} / 8.48 \\
\text { at } 90\end{array}$ & $8.50 / 9.20 /(-1.25)$ & & keeping appointments \\
\hline Refraction & $-6.25 /-0.25$ (axis180) & $+5.75 \mathrm{sph}$ & $-1.00 \mathrm{sph}$ & $-1.00 \mathrm{sph}$ & $12 \mathrm{~h}$ wear & & \\
\hline BCVA & $6 / 5$ & $6 / 5-2$ & $6 / 6-2$ & $6 / 6-2$ & $6 / 6$ & & \\
\hline (9) & & Irregular & Slightly irregular & 14 months post op & CSI soft & 17 months post op & 14-17 $h$ wear a day. No \\
\hline Keratometry & 8.18 at $180 / 8.00$ at 90 & 9.42 at $180 / 9.00$ at 90 & 8.46 at $180 / 8.26$ at 90 & 8.30 at $5 / 8.20$ at 95 & $8.60 / 13.80 /(-1.50)$ & 8.53 at $170 / 8.39$ at 80 & problems, but VA never \\
\hline Refraction & $-3.75 /-0.50($ axis 7$)$ & $+3.50 /-2.00($ axis 175$)$ & $-0.50 /-0.50$ (axis 20) & $-1.50 /-1.50$ (axis 10$)$ & $14 \mathrm{~h}$ wear & $-1.50 /-1.50$ (axis 170$)$ & sharp due to PRK haze \\
\hline BCVA & $6 / 5-3$ & $6 / 9$ & $6 / 9+3$ hazy & $6 / 5-2$ & $6 / 5-2$ & $6 / 9+2$ & and pigment \\
\hline (10) & & Irregular & Irregular & 6 months post op & Optima 60 soft & Slightly irregular & $12-14 \mathrm{~h}$ wear a day. \\
\hline Keratometry & 8.02 at $180 / 7.67$ at 90 & 9.84 at $175 / 9.36$ at 85 & 9.02 at $15 / 8.78$ at 105 & 9.04 at $20 / 8.70$ at 110 & $9.10 / 15.00 /(-5.50)$ & 9.12 at $180 / 8.74$ at 90 & After 1.75 years had \\
\hline Refraction & $-12.25 /-1.25$ (axis 175) & $+0.50 /-1.50($ axis 10$)$ & $-5.00 /-1.00$ (axis 5) & $-5.25 \mathrm{sph}$ & $12 \mathrm{~h}$ wear & $-5.25 \mathrm{sph}$ & re-treatment \\
\hline BCVA & $6 / 9$ & $6 / 12$ & $6 / 9$ & $6 / 9$ & $6 / 6-2$ & $6 / 9$ & \\
\hline
\end{tabular}

BCVA $=$ best corrected visual acuity.

associated with any detectable corneal oedema but the patient was advised to reduce lens wearing time.

\section{Refraction}

No significant changes were noted except for the slight reduction in myopia in the two patients ( 3 and 9) refitted with soft lenses (see Table 1) and the $0.75 \mathrm{D}$ increase in myopia in one RGP patient (No 5), the correction of which was not always accepted subjectively. In patient No 5 no change in the contact lens power was found necessary as the tears beneath the contact lens provided adequate extra correction.

\section{Pachymetry}

After 10 hours' wear, only two patients ( 3 and 9) showed a significant increase in central corneal thickness. Patient No 3 had an increase of only $0.03 \mathrm{~mm}(5 \%)$ and was advised to reduce wearing time from 14 to 10 hours a day. The second patient (No 9) had $0.05 \mathrm{~mm}(10 \%)$ increase in thickness. This patient had previously shown an exaggerated corneal healing response with an associated large amount of myopic regression following PRK. The thin soft lens chosen (CSI 8.60/13.80 (-1.50)) had satisfactory oxygen transmissibility and the patient was therefore advised to reduce the lens wearing time. No other changes were noted.

\section{Slit-lamp examination}

No significant adverse signs-for example, epithelial staining or limbal vessel disturbance, were noted on repeated slit-lamp biomicroscopy. No conjunctival hyperaemia was detected at follow up examinations except for patient No 5 who had longstanding interpalpebral (3 and 9 o'clock position) conjunctival hyperaemia due to an inadequate blink pattern.

\section{Discussion}

Patients request PRK for a variety of reasons. Some dislike the sensation of contact lenses. Many tolerate lenses satisfactorily but are attracted to the prospect of improved unaided vision and freedom from the expense and nuisance of lens care.

As there are increasing numbers of patients undergoing PRK and because of regression 
and the relative lack of predictability, it can be assumed that an increasing number of patients will seek contact lens correction after PRK or excimer laser retreatment of their residual ametropia. This has been estimated to be between 10 and $15 \%$ of those undergoing $\mathrm{PRK}^{30}$ and is dependent upon the original degree of myopia and the ablation zone diameter. If the degree of myopia is higher than around -6.00 D there is an increased, and perhaps unacceptable, risk of regression..$^{7-9} 12$ If the zone diameter is small then, for treatment of high myopia, there is a further increased risk of regression-primarily due to epithelial hyperplasia and deposition of new collagen and ground substance. In addition, a reduction in best corrected visual acuity has been described by Gartry et al ${ }^{7-9}{ }^{23}$ who found that around $15 \%$ of patients lost 1 to 2 lines of Snellen-for example, from $6 / 6(20 / 20)$ to $6 / 9(20 / 30)$, at the 18 month stage. These patients were also almost exclusively among the higher myopes treated $(>-6.00 \mathrm{D})$. In the study reported here $19 \%(15 / 80)$ of patients were unhappy with their visual outcome.

CONTACT LENS FITTING AFTER PRK

By definition, those presenting for PRK may not be completely satisfied with contact lens wear and seek good unaided vision. They may be able to tolerate lenses but have difficulty in dusty environments or they may find correct contact lens hygiene and handling too troublesome. In addition, they may have a genuine intolerance to lens wear related to poor tear quality or lid problems. The contact lens practitioner therefore should consider any preexisting problems that might have prompted the patient to undergo PRK originally. These problems should be addressed and improved contact lens wear sought for the post PRK patient. This may involve the design of special lenses or instruction in the use of a different contact lens disinfection regimen. In addition, many of the patients requesting PRK dislike the sensation of contact lenses and/or the effort required for their correct wear and care. Those who still need contact lens correction after PRK are likely to request soft lenses for maximum comfort and a simple lens care or disposable lens system.

When PRK patients from our original cohort were referred for contact lens fitting the authors anticipated that there might be several problems. There was concern that in post PRK eyes the cornea might respond to contact lens wear in a different manner from that of an untreated eye. It was also hypothesised that the altered central corneal shape might lead to lens centration difficulties. In addition, since the contact lens would essentially have to 'vault' the ablation zone, it seemed likely that greater minus power in the lens would be needed to counteract the positive power of the thick tear film beneath the lens. It was possible that epithelial problems could occur, with the new hyperplastic epithelium being susceptible to hypoxia and the development of oedema and/or induced irregular astigmatism. However, very few problems were encountered in this small series. The reasons suggested for this are that the new epithelium forms good attachments to the pseudomembrane created at the time of photoablation, and can easily withstand the relatively slight mechanical trauma and hypoxia of normal contact lens wear. In most of the cases patients waited 6 to 12 months before contact lens fitting to allow the cornea to stabilise after PRK. The ablation zone diameter was small (4 to $5 \mathrm{~mm}$ ) and so the contact lens vaulted this central region with most of the 'lens bearing pressure' being on the unaffected peripheral cornea. The patients were experienced lens wearers with no previous problems with lens handling, atopic conditions, or lens related infections. RGP contact lenses were advised initially for these patients since these lenses maintain their shape and vault the ablation zone more effectively than do soft lenses. They more easily correct residual irregular astigmatism and provide better vision quality. Generally RGP lenses are better than soft lenses since the material resists protein deposition on the lens surface which can interfere with vision, comfort, and epithelial integrity.

Lens fitting proved to be more straightforward than had been expected. This was due to the relatively small ablation zone diameter (mean $4.5 \mathrm{~mm}$ ) and to the graded curvature change at the edge of the zone as described by Klyce et $a .^{31}$ In keeping with the findings of Shovlin, ${ }^{32}$ excess edge clearance and mobility of the RGP lens did not pose significant problems. It should be noted however that all of the patients in the present study had received PRK with relatively small ablation zone diameters (between 4 and $5 \mathrm{~mm}$ ). Further study is needed in order to evaluate potential contact lens fitting problems in eyes which have been treated with the larger zones (commonly $6 \mathrm{~mm}$ in diameter) available with present second generation excimer lasers. For example, it may prove more difficult to achieve an adequate contact lens fitting when a larger ablation zone diameter has been used since the characteristics of the mid peripheral 'bearing areas' may have been affected adversely leading to poor lens stability. It is possible that special 'custom made' lenses may be required to ensure optimal lens fit.

In any event, contact lens fitting of the post PRK eye would seem to differ considerably from contact lens fitting after radial keratotomy (RK) ${ }^{33-35}$ Following RK the entire corneal curvature is altered with flattening of the central area and steepening of the mid peripheral regions (the 'knee' effect ${ }^{36}$ ). This has obvious implications for contact lens fitting. Since RK incisions are, of necessity, deep, corneal strength and integrity may be compromised. Since the depth, position, and length of these incisions vary, irregular astigmatism and corneal multifocality may result. ${ }^{33-37}$ In PRK, the peripheral and mid peripheral corneal shape is not affected significantly and with newer laser software algorithms attempts have been made to provide a 'blended' transition zone between the central ablated zone and the untreated cornea. In addition, in our series, by 6 months the central corneal thickness had returned to $90 \%$ 
of the preoperative value and therefore the amount of tears pooling beneath the lens was not excessive. This situation is likely to differ considerably when a larger ablation zone is used since significant diameter dependent differences in epithelial thickness have been demonstrated recently after PRK.$^{38}$ Corneal astigmatism, either pre-existing or induced, was of low degree and caused no significant fitting problem. Previous PRK studies using relatively small diameter ablation zones have shown no statistically significant increase in astigmatism after PRK. ${ }^{8}$

\section{Conclusions}

This study has shown that patients can be successfully refitted with contact lenses following PRK and that they may be capable of wearing contact lenses for up to 14 hours a day without problems. There was no significant increase in the incidence of corneal staining, oedema, or significant changes in corneal curvature. However, several patients remained dissatisfied with lens wear. Their reasons were either disappointment that corneal haze resulting from PRK affected their best contact lens corrected visual acuity or they disliked the nuisance of contact lens hygiene and follow up.

Although this study did not compare matched groups of post-radial keratotomy (RK) patients and post PRK patients it is our impression that it is easier to fit the post PRK eye with contact lenses. This is almost certainly due to the fact that PRK produces flattening of the central corneal region without affecting the periphery. Therefore the overall fitting of a contact lens across the corneal surface is affected less than in RK where there is greater alteration of the whole corneal shape, which may lead to a wider irregular, multifocal corneal surface. ${ }^{32-35}$ A RGP lens bridges the central ablation zone and a stable fit is achieved more easily if this zone is only 4 or $5 \mathrm{~mm}$ in diameter. A soft lens masks corneal surface irregularity to a small degree but more closely follows the corneal contour compared with a RGP lens. This would lead to greater fitting problems over a wide ablation zone. A small degree of temporary central corneal curvature flattening in two soft lens cases and steepening in one RGP case was noted. These curvature changes were probably due to lid pressure transmitted to the cornea via the lens as is common in non-PRK cases. Patients were advised to avoid excessive lens wearing times.

Overall, in this small series, contact lenses gave excellent visual acuity and a significant improvement in best spectacle corrected VA in cases of mild irregular astigmatism (patient Nos 2 and 5). However, a loss of BCLCVA persisted in two cases (7 and 9) as the result of PRK induced reticular haze. These two cases and at least two others with good BCLCVA but who objected to the effort of contact lens care requested PRK retreatment. After several months' delay, to allow the haze to settle, and assessment of corneal stability, retreatment PRK was carried out. However, before PRK retreatment, further counselling is of vital importance since repeat PRK has been found to be relatively unpredictable, especially in those patients who were originally highly myopic and who demonstrated marked regression in association with significant anterior stromal haze. ${ }^{30}$ Although PRKCL and repeat PRK can help patients with residual visual problems following PRK, both procedures require close monitoring of the corneal integrity and measurements to determine whether changes in lenses or in treatment are indicated. These are particularly important because the long term effects of PRKCL and repeat PRK are as yet unknown. Further studies are needed to investigate the problems encountered when fitting contact lenses to patients who have undergone PRK with larger ablation zones.

1 Gartry DS, Kerr Muir MG, Marshall J. Excimer laser superficial keratectomy: a laboratory and clinical study. $B r$ superficial keratectomy: a labo

2 Sher NA, Bowers RA, Zabel RW, Frantz JM, Eiferman RA, Brown DC, et al. Clinical use of the $193 \mathrm{~nm}$ excimer laser in the treatment of corneal scars. Arch Ophthalmol 1991;109:491-8.

3 Stark WJ, Chamon W, Kamp MT, Enger CL, Rencs EV, Gottsch JD. Clinical follow-up of $193 \mathrm{~nm}$ ArF excimer laser photokeratectomy. Ophthalmology 1992;99:805-12.

4 O'Brart DPS, Gartry DS, Lohmann CP, Patmore AL, Kerr Muir MG, Marshall J. Treatment of band keratopathy by excimer laser phototherapeutic keratectomy: surgical techniques and long term follow up. Br $\mathcal{f}$ Ophthalmol 1993;77: 702-8.

5 Seiler T, Kahle G, Kriegerowski M, Bende T. Myopic excimer laser $(193 \mathrm{~nm})$ keratomileusis in sighted and blind human eyes. Refract Corneal Surg 1990;6:165-73.

6 Seiler T, Wollensak J. Myopic photorefractive keratectomy with the excimer laser. 1 year follow-up. Ophthalmology with the excimer

7 Gartry DS, Kerr Muir MG, Marshall J. Photorefractive keratectomy with an argon fluoride excimer laser : a clinical keratectomy with an argon fluoride excimer
study. Refract Corneal Surg 1991;7:420-35.

8 Gartry DS, Kerr Muir MG, Marshall J. Excimer laser photorefractive keratectomy-18 month follow-up. Ophthalmology 1992;99:1209-19.

9 Gartry DS, Kerr Muir MG, Lohmann CP, Marshall J. The effect of topical corticosteroids on refractive outcome and corneal haze after photorefractive keratectomy. Arch Ophthalmol 1992;110:944-52.

10 McDonald MB, Liu JC, Byrd TJ, Abdelmegeed M, Andrade HA, Klyce SD, et al. Central photorefractive keratectomy for myopia. Ophthalmology 1991;98:1327-37.

11 Ficker LA, Bates AK, Steele ADMcG, Lyons CJ, Milliken $\mathrm{AB}$, Astin $\mathrm{C}$, et al. Excimer laser photorefractive keratectomy for myopia: 12 month follow-up. Eye 1993;7:617-24. 12 Seiler T, Holschbach A, Derse M, Jean B, Genth U. Complications of myopic photorefractive keratectomy with the excimer laser. Ophthalmology 1994;101:153-60.

$13 \mathrm{Salz}$ JJ, Maguen E, Nesburn AB, Warren C, Macy JI, Hofbauer JD, et al. A two year experience with excimer laser photorefractive keratectomy for myopia. Ophthalmology 1993;100:873-82.

14 Dutt S, Steinert RF, Raizman MB, Puliafito CA. One year results of excimer laser photorefractive keratectomy for low to moderate myopia. Arch Ophthalmol 1994;112:1427-36.

15 Tengroth B, Epstein D, Fagerholm P, Hamberg-Nystrom H, Fitzsimmons TD. Excimer laser photorefractive keratectomy for myopia. Clinical results in sighted eyes. Ophthalmology 1993;100:739.

16 Sher NA, Chen V, Bowers RA, Frantz JM, Brown DC Eiferman $R$, et al. The use of the 193-nm excimer laser for myopic photorefractive keratectomy in sighted eyes. A myopic photorefractive keratectomy in sighted eyes. A

17 Sher NA, Barak M, Daya S, DeMarchi J, Tucci A, Hardten DR, et al. Excimer laser photorefractive keratectomy in high myopia. A multicenter study. Arch Ophthalmol 1992;110:935-43.

18 Sher NA, Hardten DR, Fundingsland B, DeMarchi J, Carpel E, Doughman DJ, et al. 193-nm excimer photorefractive keratectomy in high myopia. Ophthalmology 1994;101:1575-82.

19 Epstein D, Fagerholm P, Hamberg-Nystrom H, Tengroth B. Twenty four month follow-up of excimer laser photorefractive keratectomy for myopia. Ophthalmology 1994;101: 1558-64.

20 Maguen E, Salz JJ, Nesburn AB, Warren C, Macy J, Papaioannou T, et al. Results of excimer laser photorefractive keratectomy for the correction of myopia. Ophthalmology 1994;101:1548-57.

21 Kim YJ, Sohn J, Tchah H, Lee C. Photoastigmatic refractive keratectomy in 168 eyes: 6 month results. $\mathcal{F}$ Cataract Refract Surg 1994;20:387-91.

22 Taylor HR, Guest CS, Kelly P, Alpins NA. Comparison of excimer laser treatment of astigmatism and myopia. Arch Ophthalmol 1993;111:1621-6.

23 Gartry DS, Kerr Muir MG, Marshall J. The effect of topical corticosteroids on refraction and corneal haze following 
excimer laser treatment of myopia: an update. A prospective, randomized, double-masked study. Eye 1993;7:584 90 .

24 O'Brart DPS, Lohmann CP, Klonos G, Corbett MC, Pollock WST, Kerr Muir MG, et al. The effects of topical cortico-steroids and plasmin inhibitors on refractive outcome, haze, and visual performance after photorefractive keratectomy. Ophthalmology 1994;101:1565-74.

25 Piebenga LW, Matta CS, Deitz MR, Tauber J, Irvine JW, Sabates FN. Excimer photorefractive keratectomy for myopia. Ophthalmology 1993;100:1335-45.

26 O'Brart DPS, Gartry DS, Lohmann CP, Kerr Muir MG, Marshall J. Excimer laser photorefractive keratectomy for myopia : comparison of 4.00- and 5.00-millimeter ablation zones. Refract Corneal Surg 1994;10:87-94.

27 Tuft SJ, Gartry DS, Rawe IM, Meek KM. Photorefractive keratectomy: implications of corneal wound healing. $\mathrm{Br} \mathcal{f}$ Ophthalmol 1993;77:243-7.

28 Trokel SL, Srinivasan R, Braren B. Excimer laser surgery of the cornea. Am $\mathcal{f}$ Ophthalmol 1983;96:710-15.

29 Marshall J, Trokel S, Rothery S, Krueger RR. Long-term healing of the central cornea after photorefractive keratectomy using an excimer laser at $193 \mathrm{~nm}$. Ophthalmology 1988;95:1411-21.

30 Gartry DS, Larkin DFP, Flaxel CJ, Ficker LA, Steele ADMcG. Retreatment for significant regression following excimer laser photorefractive keratectomy (PRK)prospective, randomised, double-masked trial. Invest OphthalmolVis Sci (suppl) 1995;36:S190.
31 Klyce SD, Wilson SE, McDonald MB, Liu JC, Kaufman HE. Corneal topgraphy after excimer laser keratectomy. Invest Ophthalmol Vis Sci (suppl) 1991;32:721.

32 Shovlin JP. A comparison between patients wearing contact lenses following radial keratotomy and myopic photorefractive keratectomy with the excimer laser. Int Contact Lens Clin 1992;19:141-2.

33 Astin CLK. Contact lenses in abnormal ocular conditions: post-radial keratotomy. In: Phillips AJ, Stone J, eds. Contact lenses. Chapter 21. London: Butterworths, 1989: 772-82.

34 Astin CLK. Keratoreformation by contact lenses after radial keratotomy. F Ophthal Physiol Opt 1991;11:156-62.

35 Astin CLK. Contact lens fitting post-refractive surgery. In: Ruben M, Guillon M, eds. Contact lens practice. London: Chapman and Hall, 1994: Chapter 36.

36 Holladay JT, Lynn MJ, Waring GO, Gemmill M, Keehn GC, Fielding $B$. The relationship of visual acuity, refractive error and pupil size after radial keratotomy. Arch Ophthalmol 1991;109:70-6.

37 Schanzlin DJ, Santos VR, Waring GO III, Lynn M, Bourque $\mathrm{L}$, Cantillo $\mathrm{N}$, et al. Diurnal change in refraction, corneal curvature, visual acuity, and intraocular pressure after radial keratotomy in the PERK study. Ophthalmology 1986; 93:167-75.

38 Gauthier C, Epstein D, Holden BA, Tengroth B, Fagerholm P, Hamberg-Nystrom H, Sievert R. Epithelial alterations following photorefractive keratectomy for myopia. F Refract Surg 1995;11:113-8. 